\title{
Parent-Child Relationships and Psychological Challenges during Adolescence: Which Solutions?
}

\section{Gianna Mangeli ${ }^{1,2}$ and Marta Toraldo ${ }^{3 *}$}

${ }^{1}$ ISBEM Euro Mediterranean Scientific Biomedical Institute, Mesagne, Brindisi, Italy

${ }^{2}$ Department of History Society and Human Studies, University of Salento, Lecce, Italy

${ }^{3}$ University of Salento, Department of Philosophy, Lecce, Italy

\begin{abstract}
This review aims to explore some aspects of social and psychological problems of young people in Italy - from the description of the Italian family of today to the types of psychosocial interventions to be implemented - adding steps and psychological critical details to the article (see: Marta Toraldo and Maria Rita Serio (2014) "Psychological Disorders and Social Distress Affecting Today's Youth in Italy: The New Face of Adolescent Problems". J Psychol Abnorm Child 3: 114. doi:10.4172/2329-9525.1000114) to which this review serves as commentary.

The article offers food for thought on all factors within Italy which bring about the onset of youth problems and raises some issues for debate. Youth problems are evident not only on an individual level, but reflect and manifest themselves in a social and community context. The youth in Italy suffers, in fact, from all the cultural transformations that, in recent years, have hit the country: the economic crisis, unemployment, changes in family life and its balance, new forms of child abuse. Institutions have not yet started to give concrete and innovative answers.

Schools remain stable in the logic that guides their activities, focusing on core subjects, and a little on the overall development of the child/teenager growing up. Finally, schools are not able to implement the "school-work alternation" to lower the gap between the world of education and professions.
\end{abstract}

The purpose of the review is to reflect on the forms of child and adolescent discomfort and propose possible and helpful interventions.

Keywords: Liquid society; Quality of family; Parent-adolescent communication; Psychological disease; Parenting support; Rationalemotive education

\section{Introduction}

The concept of a "liquid society" by Zygmunt Bauman was picked up also by the sociologist Richard Sennett, who has illustrated the current risks of capitalism, consumerism and the spread of flexibility in the workplace. He shows that modern Western society has less certainty within a social sphere, family structures, lasting human bonds, desires, plans, and hopes.

The workers of the past decade are distressed by the future, have no time to devote to their children due to changes and instability within their lives, and they have no stable role models to convey nor did a personal history make of working experience to tell. So, as well as labor mobility creating uncertainty in adults, in the same way, it is now more difficult among adolescents to develop a stable personality, and the authority of the head of the family is disappearing due to the lack of responsibility shown to their roles and duties [1].

\section{Adolescents and Psychological Distress}

Analyzing in depth the transformations of the Italian family, the data on the birth rate emphasizes that the model of the "only child", being isolated and closed to the social world, is associated with a delay in the transition to adulthood. Adolescence becomes longer, and a new phase of the life cycle emerges: the phase of the young adult. It stands between adolescence and maturity, which includes the assumption of responsibility at both a working and emotional level, making the whole process even more complex [2]. The nuclear family models, stepfamilies or extended and those mono parenting spread out - with an increase of $22 \%$ over the past 5 years of marital separations - with all the challenges to be met by the children involved [3].

Even within different educational styles, there are new forms of "child abuse". In contemporary society the child at risk is not only the poor but the one living in an environment devoid of resources for its physical and psycho-emotional well-being that does not support the formation of his personality and his potential to be expressive. Such situations may develop depressive, psychotic, psychosomatic disorders (e.g., sleep, food, language disorders), phobias, distrust of adults, regressive behavior, inability in the regulation and control of emotions, inability to socialize and play, deviant and delinquent aspects, disorders associated with substance abuse, alcoholism and even suicide attempts [4].

However, recent data of the National Observatory for Children and Adolescents in Italy has shown that on average 9 out of 10 children in Italy express satisfaction with the relations and the ties they have with their families. With the exception of single parent families, for the majority of Italian families, the parent-child relations are characterized mainly in positive terms [5].

Positive family relations promote the adoption of values. Also, the acceptance by adolescents of the values transmitted by the family is facilitated by the coherence that they perceive between what adults say and what behavior they practice [6]. Another factor that facilitates the transmission of values is the consonance between the two parents [7].

On the question of how and where you can take action to maintain and support the psychophysical wellbeing of children and adolescents, I fully agree with what was stated in the article "Families are alarmed and schools do not know what to do" as well as the belief that schools and

*Corresponding author: Marta Toraldo, Department of Philosophy, University of Salento, Lecce, Italy, Tel: +393358022958; E-mail: d.torald@tin.it

Received June 01, 2015; Accepted August 08, 2015; Published August 15, 2015

Citation: Mangeli G, Toraldo M (2015) Parent-Child Relationships and Psychological Challenges during Adolescence: Which Solutions? J Psychol Abnorm Child 4: 145. doi:10.4172/2329-9525.1000145

Copyright: ( $) 2015$ Mangeli G, et al. This is an open-access article distributed under the terms of the Creative Commons Attribution License, which permits unrestricted use, distribution, and reproduction in any medium, provided the original author and source are credited. 
families should cooperate through "a program to improve the Italian education system." So, policies are needed within schools to prevent the causes of abandonment with diversified training after school, and design support measures for critical situations. In addition, family policies are needed to enable the creation of welfare measures for networking among those closely involved. The exchange family-community seems to be the critical point [8].

Therefore, families and schools should become the privileged places of interventions in favor of children and adolescents, capable of promote changes as well as develop protection factors for the welfare of youth. The support of parents has increased in last years because, as demonstrated by Nobel Prize in Economics James J Heckmann, investing in early childhood, especially the ones considered at risk, ensures greater returns in terms of education, health and productivity [9]. The qualities of family relationships, in turn, reflect the quality of social relations and the entire society [10]. At the same way, focusing on the teaching in schools is the royal road to activate paths of RationalEmotive Education and Affective-Relational Education. Schools also become the place of development of the "eight key competences" which, taken up in the renewed Lisbon Strategy in 2005, are among the objectives of the work program "Education and Training 2010" [11].

Young people must be helped to develop social skills, and the development of all other skills allows them to live with awareness in every context of life. The key competences for lifelong learning are necessary for personal awareness and development, active citizenship, social inclusion and employment, essential in a knowledgeable society such as ours [12]. They provide more flexibility for young students and workers to adapt more quickly to a changing world which is increasingly interconnected and competitive. The key competences are all interdependent, and every time the emphasis is on critical thinking, creativity, initiative, problem solving, risk assessment, decision-making and the positive management of emotions. The eight key competences are: communication in the mother tongue, communication in foreign languages, mathematical competence and basic competences in science and technology, digital competence, learning to learn, social and civic competences, sense of initiative and entrepreneurship, cultural and expression awareness. Subsequently we need to focus on schools that, as secondary agencies of socialization after families, should provide useful tools to detect risk factors and promote those of protection, to form men of tomorrow and provide the necessary soft skills, useful for every field of existence.

\section{Conclusion and Outlook}

Reflections and data presented highlight the crucial role of families in the complex psychological dynamics of young people. They on one hand, confirm its central role for the growth of the younger generation [12] and on the other, deal with the difficulty of the education of children in an authoritative way.

For this reason, we must invest pedagogically in parents and their capacity to educate, which should be enhanced through paths of reflection.

There are no perfect parents but there are parents who are "good enough" [13], committed to building and maintaining an emotional positive climate within the family. Turco Law Italian n. 285/97 (Legge 28 agosto 1997, n. 285 Disposizioni per la promozione di diritti e di opportunità per l'infanzia e l'adolescenza) states that "The development of good family relations must be supported by adequate network of services, able also to appreciate community networks, exchange and an assistance among families."

The educational institution as school must include not only the ordinary teaching subjects but also activities to strengthen the emotional, relational, adaptive resources of children, conducted with the support of educators and psychologists.

\section{References}

1. Sennet $R$ (1998) The Corrosion of Character: The personal consequences of work in the New Capitalism, Norton.

2. Scabini E, Marta Rizzi E, Lanz M (2006) Transition to adulthood and family relations: An Intergenerational Perspective, Taylor and Francis Ltd. London ,United Kingdom.

3. Fosco GM, Feinberg ME (2015) Cascading effects of interparental conflict in adolescence: Linking Threat Appraisals, Self-Efficacy and Adjustment, Development and Psychopathology 27: 239-252.

4. O'Mahen HA, Karl A, Moberly N (2015) The association between childhood maltreatment and emotion regulation: Two different mechanisms contributing to depression? J Affect Disord 174: 287-295.

5. Presidency of the Council of Ministers, Department for family policies - Ministry of Labor, Health, Social Policy - National Observatory for Children and Adolescents, Institute of Innocence in Florence (2013) Report on the Condition of Childhood and Adolescence, Themes and perspectives from the work of the National Observatory for Childhood and Adolescence, Del Gallo publishers.

6. Barni D, Ranier S, Scabini E (2012) Value similarity among Grandparents, Parents and Adolescent Children: Unique or Stereotypical? Family Science 9: 46-54.

7. Donato S, Lafrate R, Bradbury T, Scabini E (2012) Acquiring dyadic coping: Partners and parents as models, Personal Relationships 15: 386-400.

8. Eisenberg N, Van Schyndel SK, Hofer C (2015) The Association of Maternal Socialization in childhood and adolescence with adult offspring's sympathy/ caring, Dev Psychol 51: 7-16.

9. Heckman J, Cunha F (2009) Investing in our Young People, Rivista internazionale di scienze sociali 117: 365-386.

10. Bandura A, Caprara GV, Barbaranelli C, Regalla C, Scabini E (2011) Impact of Family Efficacy Beliefs on Quality of Family Functioning and Satisfaction with Family Life. Appl Psychol 28: 421-448.

11. Steffens K (2015) Competences, Learning Theories and MOOCs: Recent Developments in Lifelong Learning, Recommendation 2006/962/EC of the European Parliament and of the Council. European Journal of Education 50: 41-59.

12. Inguglia C, Ingoglia S, Liga F (2015) Autonomy and Relatedness in Adolescence and Emerging Adulthood: Relationships with Parental Support and Psychological Distress. J Adult Dev 22: 1-13.

13. Winnicott D (1994) Talking To Parents, Paperback. 